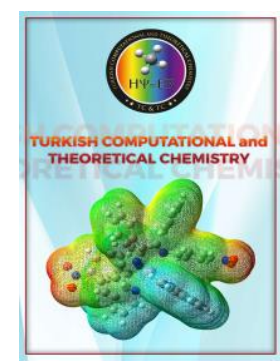

Received: 22.10 .2020
Turkish Computational and Theoretical Chemistry

Turkish Comp Theo Chem (TC\&TC)

Volume(Issue): 5(1) - Year: 2021 - Pages: 1-12

e-ISSN: 2602-3237

https://doi.org/10.33435/tcandtc.814554

Accepted: 21.12 .2020

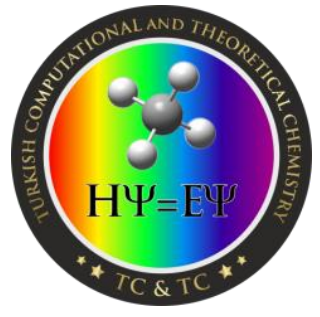

Research Article

\title{
2-Phenylethyne-1-Sulfonamide Derivatives as New Drugs Candidates for Heat Shock Protein 70 and Doublecortin-like Kinase
}

\author{
Mustafa ERGÜL ${ }^{a}$, Koray SAYIN ${ }^{b, c, ~}$, , Hilmi ATASEVEN ${ }^{d}$ \\ ${ }^{a}$ Department of Biochemistry, Faculty of Pharmacy, Sivas Cumhuriyet University, 58140 Sivas - \\ TURKEY \\ ${ }^{b}$ Department of Chemistry, Faculty of Science, Sivas Cumhuriyet University, 58140 Sivas - TURKEY \\ ${ }^{c}$ Advanced Technology Research and Application Center, Sivas Cumhuriyet University, 58140 Sivas - \\ TURKEY \\ ${ }^{\mathrm{d} D e p a r t m e n t ~ o f ~ G a s t r o e n t e r o l o g y, ~ F a c u l t y ~ o f ~ M e d i c i n e, ~ S i v a s ~ C u m h u r i y e t ~ U n i v e r s i t y, ~ S i v a s ~ T U R K E Y ~}$
}

\begin{abstract}
Under physiological conditions HSP70 plays crucial roles in protein homeostasis. This protein is overexpressed in many types of cancer cells and increased levels of HSP70 is closely associated with tumorigenesis and poor clinical outcomes. The present study was designed to evaluate in silico assessment of newly designed 30 different 2-Phenylethyne-1-Sulfonamide derivatives potential heat shock protein 70 inhibitors. The mentioned structures were optimized at B3LYP/6-31+G(d,p) level in water and active sites of them are determined. Then, molecular docking calculations were done between the related structures and $4 \mathrm{PO} 2$ and 5JZN. It is found that compound (5), (12) and (20) were found as the better ones than those of compound (1) and (2). Drug likeness studies were performed via pharmacological ADME (absorption, distribution, metabolism, and excretion) properties estimation and the drug properties of (5) and (12) were found as the better than those of compound (1), (2) and (20).
\end{abstract}

Keywords: HSP70 Inhibitors, Drug Design, Molecular Dynamics, Molecular Docking, ADME Analyses

\section{Introduction}

Heat shock proteins (HSPs) are highly evolutionarily conserved molecular chaperones whose expression is induced by several physiological and environmental insults such as: hyperthermia, hypoxia, toxins, viral infections, ischemia, heavy metals, chemotherapy and cancer [1]. HSPs have been shown to participate in various crucial processes such as: protein folding, protein assembly/disassembly, repair, secretion, trafficking, refolding of misfolded peptides, and involvement in intracellular protein transport [2]. Mammalian HSPs are generally classified according to their molecular weights: HSP100, HSP90, HSP70, HSP60 and the small HSPs [3]. Among them, Hsp70 family is one of the best studied, most common and evolutionary conserved chaperone that is found in every membranous organelle of all cells [4]. It has been reported that human cells contain at least $13 \mathrm{Hsp} 70$ isoforms including stress inducible cytosolic Hsp70 (HSPA1A, HSPA1B) and constitutively expressed cytosolic heat shock cognate (HSC70) which are two main cytoplasmic forms [5]. Hsp70 isoforms exhibit a similar domain structure and they are composed of a $\sim 44 \mathrm{kDa} \mathrm{N}$-terminal nucleotidebinding domain (NBD) that possesses ATPase activity, a $\sim 28-\mathrm{kDa}$ C-terminal polypeptide substrate-binding domain (SBD) that recognizes and binds extended polypeptide substrates. Moreover, these two domains are connected to each other via a short and highly conserved flexible linker [6,7]. Hsp70 family members are involved in several protein-folding process for the maintenance of protein homeostasis [8,9]. In addition to protein folding and homeostasis roles, Hsp70 also plays important roles in cancer development, tumor cell survival and tumor growth [3]. It is known that malignant cells have higher metabolic requirements than healthy cells; therefore, they have higher need

\footnotetext{
${ }^{1}$ Corresponding Authors

e-mail: krysayin@gmail.com, ksayin@cumhuriyet.edu.tr
} 
of HSPs than normal cells [10]. Under physiological conditions, Hsp70 is marginally expressed in healthy cells; however, Hsp70 expression levels are significantly increased in various types of tumor cells [11]. Furthermore, Hsp70 inhibits apoptosis both in intrinsic and extrinsic pathways and increased levels of Hsp70 in human tumors is closely related with high invasiveness, higher resistance to anticancer treatment, increased cell proliferation rate, low survival rate and poor prognosis [12,13]. For these reasons, specific inhibition of Hsp70 in tumor cells by specific chemical inhibitors is an attractive strategy for cancer therapy [14,15]. There are several Hsp70 inhibitors that bind to NBD or SBD and inhibit its chaperon functions [16]. One of them<smiles>[R]c1c([R])c([R])c(C#C[Si](N)(=O)=O)c([R3])c1[R]</smiles>

\begin{tabular}{|c|c|c|c|c|}
\hline Compound Number & $\mathbf{R}_{1}$ & $\mathbf{R}_{2}$ & $\mathbf{R}_{\mathbf{3}}$ & $\mathbf{R}_{4}$ \\
\hline (1) & $\mathrm{H}$ & $\mathrm{H}$ & $\mathrm{H}$ & $\mathrm{H}$ \\
\hline (2) & $\mathrm{H}$ & $\mathrm{Cl}$ & $\mathrm{H}$ & $\mathrm{H}$ \\
\hline (3) & $\mathrm{H}$ & $\mathrm{H}$ & $\mathrm{Cl}$ & $\mathrm{H}$ \\
\hline (4) & $\mathrm{Cl}$ & $\mathrm{H}$ & $\mathrm{Cl}$ & $\mathrm{H}$ \\
\hline (5) & $\mathrm{Cl}$ & $\mathrm{H}$ & $\mathrm{Cl}$ & $\mathrm{H}$ \\
\hline (6) & $\mathrm{H}$ & $\mathrm{H}$ & $\mathrm{F}$ & $\mathrm{H}$ \\
\hline (7) & $\mathrm{F}$ & $\mathrm{H}$ & $\mathrm{F}$ & $\mathrm{H}$ \\
\hline (8) & $\mathrm{F}$ & $\mathrm{H}$ & $\mathrm{F}$ & $\mathrm{H}$ \\
\hline (9) & $\mathrm{H}$ & $\mathrm{H}$ & $\mathrm{Br}$ & $\mathrm{H}$ \\
\hline (10) & $\mathrm{Br}$ & $\mathrm{H}$ & $\mathrm{Br}$ & $\mathrm{H}$ \\
\hline (11) & $\mathrm{Br}$ & $\mathrm{H}$ & $\mathrm{Br}$ & $\mathrm{H}$ \\
\hline (12) & $\mathrm{Cl}$ & $\mathrm{Cl}$ & $\mathrm{Cl}$ & $\mathrm{Cl}$ \\
\hline (13) & $\mathrm{F}$ & $\mathrm{F}$ & $\mathrm{F}$ & $\mathrm{F}$ \\
\hline (14) & $\mathrm{Br}$ & $\mathrm{Br}$ & $\mathrm{Br}$ & $\mathrm{Br}$ \\
\hline (15) & $\mathrm{H}$ & $\mathrm{H}$ & $\mathrm{NO}^{-}$ & $\mathrm{H}$ \\
\hline (16) & $\mathrm{H}$ & $\mathrm{NO}^{-}$ & $\mathrm{H}$ & $\mathrm{H}$ \\
\hline (17) & $\mathrm{NO}^{-}$ & $\mathrm{H}$ & $\mathrm{H}$ & $\mathrm{H}$ \\
\hline (18) & $\mathrm{H}$ & $\mathrm{H}$ & $\mathrm{CN}^{-}$ & $\mathrm{H}$ \\
\hline (19) & $\mathrm{H}$ & $\mathrm{CN}^{-}$ & $\mathrm{H}$ & $\mathrm{H}$ \\
\hline (20) & $\mathrm{CN}^{-}$ & $\mathrm{H}$ & $\mathrm{H}$ & $\mathrm{H}$ \\
\hline (21) & $\mathrm{H}$ & $\mathrm{H}$ & $\mathrm{OH}^{-}$ & $\mathrm{H}$ \\
\hline (22) & $\mathrm{H}$ & $\mathrm{OH}^{-}$ & $\mathrm{H}$ & $\mathrm{H}$ \\
\hline (23) & $\mathrm{OH}^{-}$ & $\mathrm{H}$ & $\mathrm{H}$ & $\mathrm{H}$ \\
\hline (24) & $\mathrm{H}$ & $\mathrm{H}$ & $\mathrm{CO}$ & $\mathrm{H}$ \\
\hline (25) & $\mathrm{H}$ & $\mathrm{CO}$ & $\mathrm{H}$ & $\mathrm{H}$ \\
\hline (26) & $\mathrm{CO}$ & $\mathrm{H}$ & $\mathrm{H}$ & $\mathrm{H}$ \\
\hline (27) & $\mathrm{H}$ & $\mathrm{H}$ & NO & $\mathrm{H}$ \\
\hline (28) & $\mathrm{H}$ & NO & $\mathrm{H}$ & $\mathrm{H}$ \\
\hline (29) & NO & $\mathrm{H}$ & $\mathrm{H}$ & $\mathrm{H}$ \\
\hline
\end{tabular}

is 2-phenylethyenesulfonamide (PES); also known as pifithrin- $\mu$ selectively interacts with the $\mathrm{C}$ terminal PBD of endogenous Hsp70 and disrupts its association with co-chaperones and substrate polypeptides $[10,17]$. This compound also displays significant anti-cancer effect on various human cancer cell types such as: breast cancer, head and neck cancer, and lung cancer. Moreover, currently it has been discovered that the chlorinated version of pifithrin- $\mu$ (PES-Cl) has more potent anti-cancer activities than PES [18]. According to this information, in the present study a series of PES derivatives were designed and evaluated for their interactions with inducible Hsp70 using the Schrödinger program.

Schema 1. Structures and names of designed drug candidates.

In computational chemistry application, twenty nine molecules was designed which are represented in Schema 1 with their name. The related compounds are optimized at B3LYP/6-31+G(d,p) level in water. Molecular orbital energy diagram, contour plots of the important molecular orbitals and molecular electrostatic potential map and molecular electrostatic potential contours are examined in detail. At the present time, 2-phenylethye-1-sulfonamide (1) and 2-(3-cholorophenyl)ethyne-1-sulfonamide (2) are used as commercial compounds. In addition to these data, it is known that the compound (2) exhibits better 
results than compound (1) in the inhibition of HSP70 protein. These compounds are converted PDB format and related compounds are interacted with target proteins which PDB IDs are 4PO2 and 5JZN. 4PO2 is related with HSP70 protein while 5JZN is related with Doublecortin-like Kinase Domain 1 (DCLK1). This protein is highly expressed in gastric cancer. Otherwise, DCLK1 is among the 15 most common putative driver genes for gastric cancers. In molecular docking calculation, OPLS3 method is used. The interactions between compound candidates and target proteins are investigated and compared with the results of compound (1) and (2) in detail. The better compound candidates than compound (1) and (2) are examined with SwissADME web tool to evaluate pharmacokinetics, compound-likeness and medicinal chemistry friendliness. As a result, the better compounds were determined as compound (5), (12) and (20). These compounds can be synthesized and can take the place of existing compounds.

\section{Computational Method}

The mentioned compound were prepared using GaussView 5.0.8 and ChemDraw Proffesional 15.1 programs [19,20]. Quantum chemical calculations of the prepared input files of studied compound candidates were performed by using Gaussian AS64L-G09RevD.01 [21] program at B3LYP [22], one of the hybrid density functional theory (DFT) functions, with 6-31+G(d,p) basis set [23-31]. Molecular orbital energy diagram was redrawn by the selecting of degeneracy threshold as 0.01 a.u. Degeneracy molecular orbitals to frontier molecular orbitals are determined and contour plots of them were calculated at same level of theory by using Gaussian IA32W-G09RevA.02 program [32]. Additionally, density of state (DOS) spectrum of related compounds was calculated by using GaussSum 3.0 program [33] and examined in detail. Molecular electrostatic potential (MEP) map and contours were obtained by the calculation of electrostatic potential (ESP) charges. These charges were calculated by using Gaussian IA32WG09RevA.02 program. The interactions between ligand and target proteins were investigated at OPLS3 method [34] by using Schrödinger Maestro XXX program [35-37]. Finally, absorption, distribution, metabolism and excretion of compound candidates are evaluated by using SwissADME web tool [38,39]. In this way, the most efficient compounds were determined. The crystal structures of homo sapiens Hsp70 PBD (PDB code: 4PO2) [40] and homo sapiens Doublecortin-like Kinase Domain 1 (PDB code: 5JZN) [41] were downloaded from RCSB Protein Data Bank (PDB, www.rcsb.org).

\section{Results and discussion}

\subsection{Electronic Structure at Ground State}

The related chemical are fully-optimized at B3LYP/6-31+G(d,p) level in water. Any imaginary frequecy is obtained from frequency calcualations. The optimized structures of the mentioned compounds are represented in Figure 1. Some structural parameters are reported.

According to Figure 1, the whole structures are generally similar to each other. The calculated bond lengths between $\mathrm{C}-\mathrm{C} ; \mathrm{C}-\mathrm{H} ; \mathrm{C} \equiv \mathrm{C} \mathrm{C}-\mathrm{S} ; \mathrm{S}-\mathrm{O}$ and $\mathrm{S}-\mathrm{N}$ are calculated nearly $1.402 \AA ; 1.214 \AA ; 1.084 \AA$; $1.716 \AA ; 1.468 \AA$ and $1.662 \AA$, respectively. As theoretically, the structure containing the triple bond is expected to be flat. However, the torsion angles in $S_{1}-C_{1}-C_{2}-C_{3}$ are calculated nearly $-169.86^{\circ}$ due to the fact that the $\pi$ electrons are not localized between carbon atoms. In the IR spectrum, imaginary frequency is not observed and it implies that the all structure is at ground state.

\subsection{Molecular Orbital Energy Diagram, Contour Plots and Density of State Spectrum}

Molecular orbital energy diagram (MOED) of related chemicals are drawn by the selecting of degeneracy threshold as 0.01 a.u. Molecular orbitals energy diagrams of compound (1), (2), (5), (12) and (20) are represented in Figure 2. The other MOEDs of the other ones are represented in Supp. Figure S1 in Supplemental Information.

It can be easily seen the degeneracy molecular orbitals to frontier molecular orbitals which are the highest occupied molecular orbital (HOMO) and the lowest unoccupied molecular orbital (LUMO) are determined from Figure 2. The molecular orbitals are important in the determination of chemical reactivity of chemicals. As generally, molecular orbitals give important information about interaction mechanism, active regions, electronic freedom and etc. Significant molecular orbitals are mainly determined as HOMO and LUMO. Additionally, HOMO-1 is important for compound (12). Contour plots of these molecular orbitals are calculated. 
Turkish Comp Theo Chem (TC\&TC), 5(1), (2021), 1-12

Mustafa ERGÜL, Koray SAYIN, Hilmi ATASEVEN

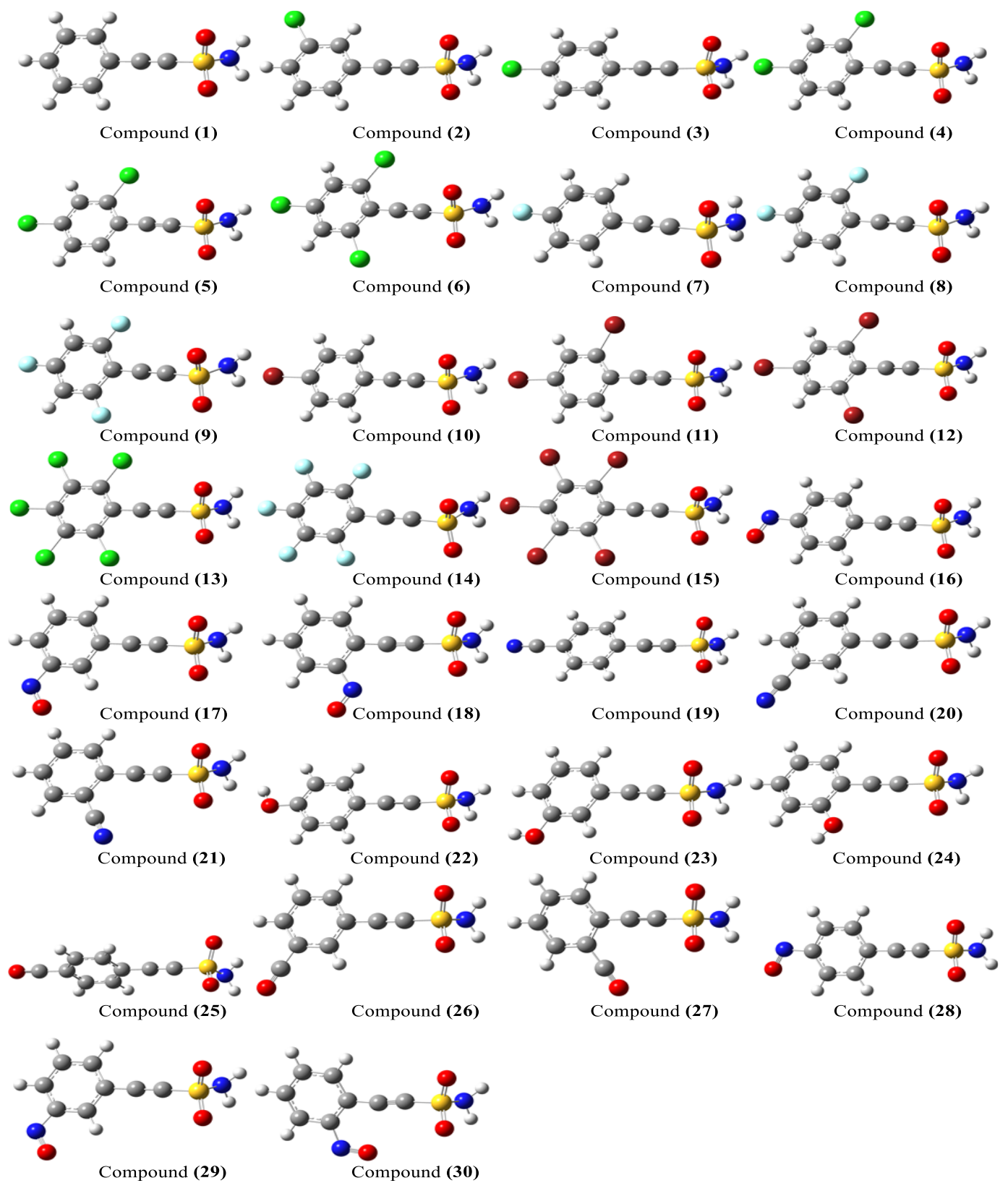

Figure 1. Optimized structures of studied compounds.
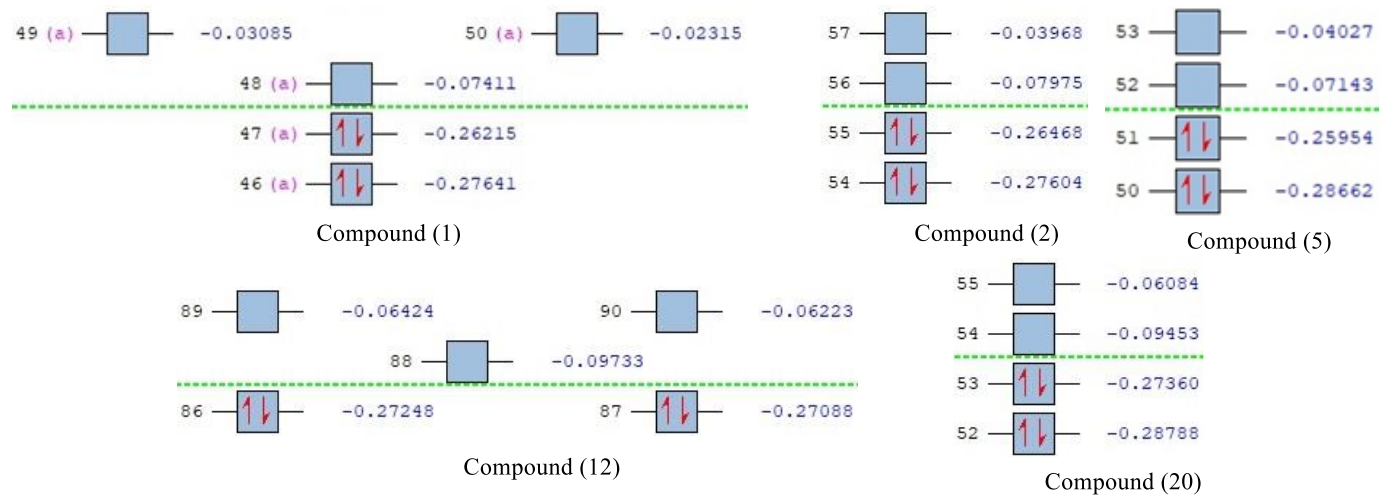

Figure 2. The calculated molecular orbital energy diagram of mentioned compounds. 
The related contour plots of mentioned compounds are represented in Figure 3. Contour plots of the others are given in Supplementary Information.

According to Figure 3, two electrons in HOMO are mainly delocalized on the whole structure. The effect of sulfonamide group in related compounds in the formation of contour plots of HOMO is lower than those of benzene rings. Additionally, $\pi$ electrons are dominant in the formation of HOMO contour plots. The interactions will be occurred mainly from $\pi$ electrons. Additionally, chemical properties of heteroatoms and electronic charges of atoms will affect the interaction strength and mechanism of compounds. As for the LUMO, similar evaluations can be done for them. However, the effects of hetero atoms in contour plots of LUMO are lower than those of HOMO ones. Density of state spectrum are calculated to investigate the proximity of molecular orbitals to each other. This spectrum can be useful in the determination of electronic properties of related compound candidates. The gap between occupied and unoccupied molecular orbitals can be easily seen from these spectra. The mentioned spectrum are calculated for each chemicals. DOS spectrum of compound (1), (2), (5), (12) and (20) are given in Figure 4. The DOS spectrum of the other related chemicals are given in Supplementary Information. The occupied molecular orbitals are represented by green line while the unoccupied molecular orbitals are represented via red lines. According to Figure 4, the value of energy gap between occupied and unoccupied molecular orbitals is often similar to each other in each compound. Additionally, molecular orbitals are mainly gathered between -10 $-+10 \mathrm{eV}$ range. The intensity of DOS spectrum of unoccupied molecular orbitals are similar to each other. However, there are some differences in the DOS spectrum of the occupied molecular orbitals. This point is important in the determination of target compounds. The occupied molecular orbitals are close to each other in terms of energy, especially in the first ten compounds. These outcomes canalize the direction of the project to the focusing the first ten compounds. However, the whole compounds is examined in detail in this study.
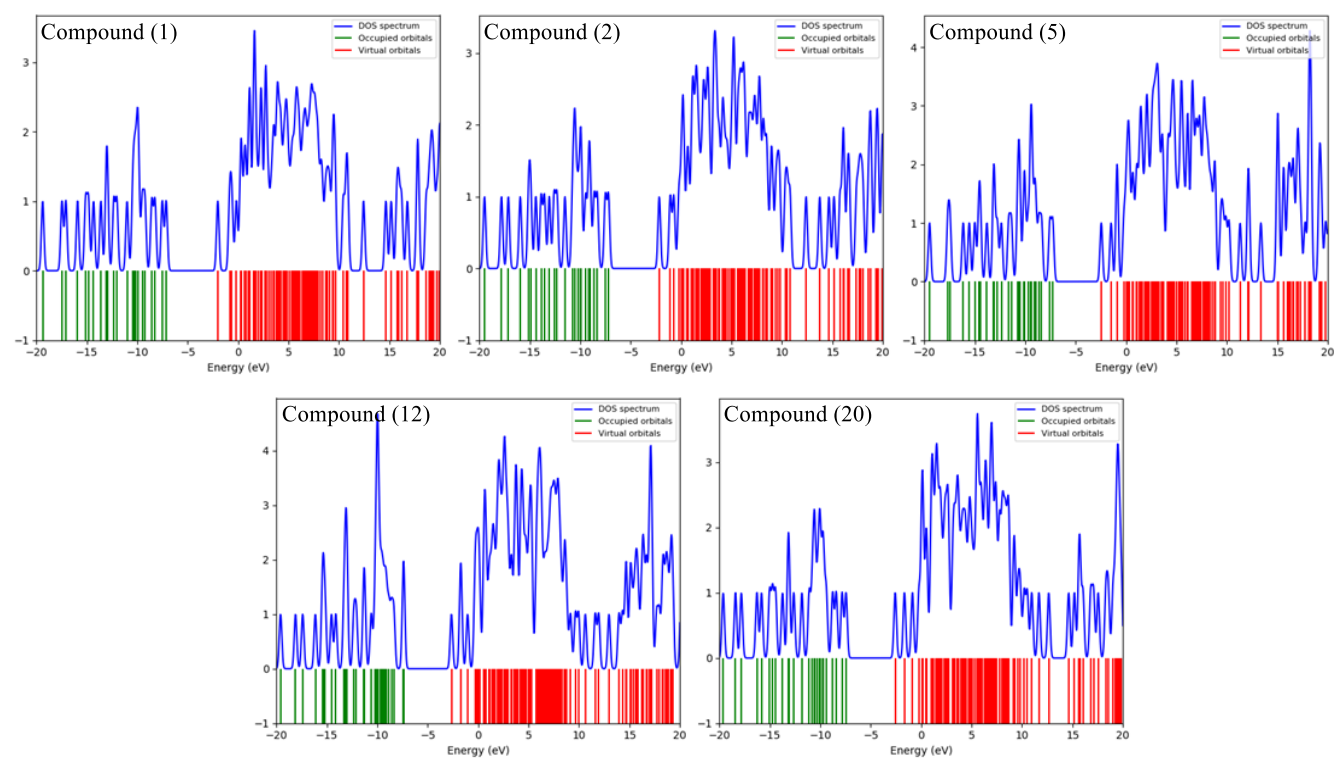

Figure 4. DOS spectrum of the compound (1), (2), (5), (12) and (20).

\subsection{Molecular Electrostatic Potential Map and Contour}

Molecular electrostatic potential (MEP) map and contour are significant to determine the electrophilic active regions to any interactions. The electrostatic potential load helps the molecular surface to be stained in different colors, thus identifying the active site. MEP maps and contours of compound (4) - (9) are represented in Figure 5 and the other MEP maps and contour for the other compounds are represented in Supplementary Information. 
According to Figure 5, there are different color zone in MEP maps. The red color represents the electrophilic active region while dark blue implies the nucleophilic active region. The electrostatic charges on molecular surface inhibit the differences respect to substituent effects. In the related compounds, $\pi$ electrons are active and these electrons are appropriate to any interaction with the target protein. Additionally, the effect of heteroatoms to the surface charge distribution can be seen easily from these maps. Especially, the cyanide group enhanced the reactivity of compounds. In addition to these results, chlorine atoms show the same effect such as cyanide group. According to MEP maps, compound (5), (12) and (20) is more reactive than those of compound (1) and (2).

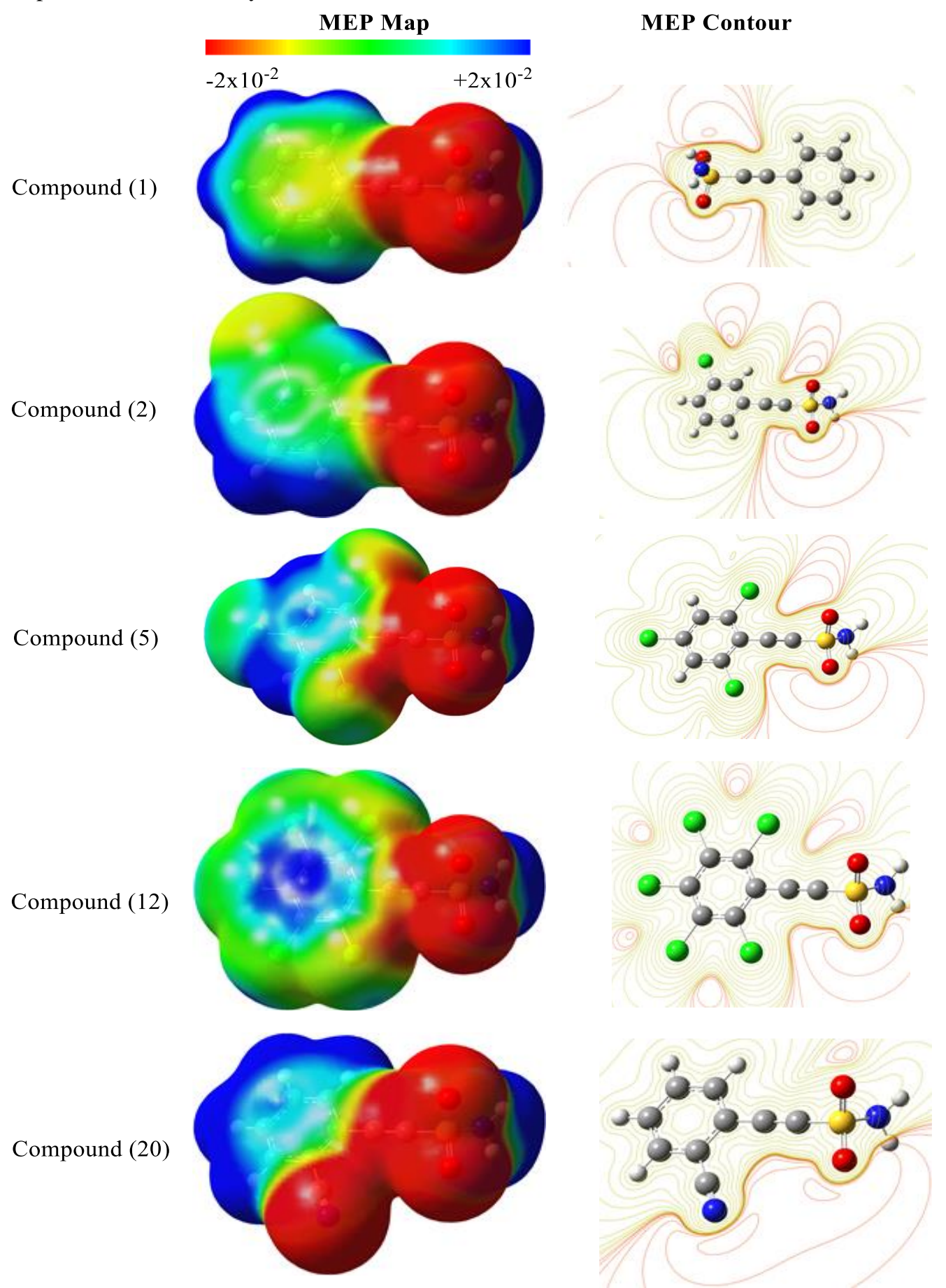

Figure 5. Calculated MEP map and contours of the mentioned compounds. 


\subsection{Molecular Docking}

Molecular docking calculations between related compounds and target proteins which belong to heat shock protein 70 (HSP4A) and Doublecortinlike Kinase (DCLK). These targets are examined in protein data bank and 4PO2 and 5JZN are selected for HSP4A and DCLK, respectively. The first one is the member of molecular chaperones. The functions of HSP70 are the maintain protein quality control and homeostasis. It is accepted that HSP4A is the target of the anti-cancer compounds due to the constitutively overexpressed in a number of human cancers and promotes cancer cell survival [23]. The latter one is one of the doublecortin-like kinase domain 1 (DCLK1) protein. DCLK1 is among 15 driver genes for gastric cancer [24]. It is reported that HSP4A is determined in stomach cancer. The inhibition of these proteins can be seen as one of the anticancer steps. Molecular docking calculations are performed at OPLS3e method by using Maestro Schrödinger program. Interaction energies and docking score are given in Table 1.

Table 1. Calculated docking score and interaction energies between related compounds and target proteins.

\begin{tabular}{|c|c|c|c|c|c|c|c|c|c|}
\hline \multirow[b]{2}{*}{ Comp. } & \multicolumn{2}{|c|}{$4 \mathrm{PO} 2$} & \multicolumn{2}{|c|}{$5 \mathrm{JZN}^{\mathrm{a}}$} & \multirow[b]{2}{*}{ Comp. } & \multicolumn{2}{|c|}{$4 \mathrm{PO} 2$} & \multicolumn{2}{|c|}{$5 \mathrm{JZN}^{\mathrm{a}}$} \\
\hline & $\begin{array}{l}\text { Docking } \\
\text { Score }^{\mathrm{b}}\end{array}$ & $\begin{array}{l}\text { Interaction } \\
\text { Energy }^{\mathrm{b}}\end{array}$ & $\begin{array}{l}\text { Docking } \\
\text { Score }^{b}\end{array}$ & $\begin{array}{l}\text { Interaction } \\
\text { Energy }^{\mathrm{b}}\end{array}$ & & $\begin{array}{l}\text { Docking } \\
\text { Score }^{b}\end{array}$ & $\begin{array}{l}\text { Interaction } \\
\text { Energy }^{\mathrm{b}}\end{array}$ & $\begin{array}{l}\text { Docking } \\
\text { Score }^{b}\end{array}$ & $\begin{array}{l}\text { Interaction } \\
\text { Energy }^{\mathrm{b}}\end{array}$ \\
\hline 1 & -1.689 & -24.406 & $\begin{array}{l}-4.322 \\
(-3.372)\end{array}$ & $\begin{array}{l}-18.696 \\
(-16.571)\end{array}$ & 16 & -2.585 & -18.917 & $\begin{array}{l}\text { No Pose } \\
\left(\text { No Pose }^{\mathrm{c}}\right)\end{array}$ & $\begin{array}{l}\text { No Pose } e^{c} \\
\left(\text { No Pose }^{c}\right)\end{array}$ \\
\hline 2 & -2.276 & -18.252 & $\begin{array}{l}-3.884 \\
(-3.601)\end{array}$ & $\begin{array}{l}-22.495 \\
(-21.609)\end{array}$ & 17 & -0.386 & -20.876 & $\begin{array}{l}-4.089 \\
(-3.514)\end{array}$ & $\begin{array}{l}-24.208 \\
(-22.723)\end{array}$ \\
\hline 3 & & & & & 18 & -0.072 & -15.481 & $\begin{array}{l}-3.846 \\
(-3.834)\end{array}$ & $\begin{array}{l}-22.999 \\
(-21.117)\end{array}$ \\
\hline 4 & -0.339 & -16.314 & $\begin{array}{l}-4.376 \\
\left(\text { No Pose }^{\mathrm{c}}\right)\end{array}$ & $\begin{array}{l}-21.566 \\
(\text { No Pose })\end{array}$ & 19 & -2.573 & -15.005 & $\begin{array}{l}-4.649 \\
(-3.557)\end{array}$ & $\begin{array}{l}-21.039 \\
(-22.456)\end{array}$ \\
\hline 5 & -2.341 & -28.237 & $\begin{array}{l}-3.839 \\
(-4.246)\end{array}$ & $\begin{array}{l}-26.318 \\
(-21.802)\end{array}$ & 20 & -2.423 & -26.409 & $\begin{array}{l}-4.735 \\
\left(\text { No Pose }^{c}\right)\end{array}$ & $\begin{array}{l}-22.612 \\
\left(\text { No Pose }^{\mathrm{c}}\right)\end{array}$ \\
\hline 6 & -2.379 & -16.154 & $\begin{array}{l}-4.287 \\
\left(\text { No Pose }^{c}\right)\end{array}$ & $\begin{array}{l}-21.620 \\
\left(\text { No Pose }^{c}\right)\end{array}$ & 21 & -1.888 & -22.803 & $\begin{array}{l}-3.813 \\
(-3.975)\end{array}$ & $\begin{array}{l}-18.622 \\
(-20.969)\end{array}$ \\
\hline 7 & -0.191 & -15.689 & $\begin{array}{l}-4.545 \\
(-3.717)\end{array}$ & $\begin{array}{l}-21.620 \\
(-16.724)\end{array}$ & 22 & -2.919 & -17.868 & $\begin{array}{l}-4.059 \\
(-4.951)\end{array}$ & $\begin{array}{l}-20.127 \\
(-18.089)\end{array}$ \\
\hline 8 & -0.874 & -21.239 & $\begin{array}{l}-4.147 \\
(-4.101)\end{array}$ & $\begin{array}{l}-17.113 \\
(-23.116)\end{array}$ & 23 & -1.662 & -25.994 & $\begin{array}{l}-4.956 \\
(-4.577)\end{array}$ & $\begin{array}{l}-21.597 \\
(-23.874)\end{array}$ \\
\hline 9 & -1.773 & -23.063 & $\begin{array}{l}-4.388 \\
(-4.562)\end{array}$ & $\begin{array}{l}-19.835 \\
(-23.273)\end{array}$ & 24 & No Pose $e^{c}$ & No Pose ${ }^{c}$ & $\begin{array}{l}\text { No Pose } \\
\left(\text { No Pose }^{c}\right)\end{array}$ & $\begin{array}{l}\text { No Pose } \\
(\text { No Pose } \\
(\text { c })\end{array}$ \\
\hline 10 & -0.065 & -22.220 & $\begin{array}{l}-4.164 \\
(-4.708)\end{array}$ & $\begin{array}{l}-23.171 \\
(-24.988)\end{array}$ & 25 & No Pose $e^{c}$ & No Pose ${ }^{c}$ & $\begin{array}{l}\text { No Pose } \\
\left(\text { No Pose }^{c}\right)\end{array}$ & $\begin{array}{l}\text { No Pose }{ }^{c} \\
\left(\text { No Pose }^{c}\right)\end{array}$ \\
\hline 11 & -2.084 & -29.397 & $\begin{array}{l}\text { No Pose } \\
(-4.102)\end{array}$ & $\begin{array}{l}\text { No Pose } \\
(-22.997)\end{array}$ & 26 & No Pose & No Pose ${ }^{c}$ & $\begin{array}{l}\text { No Pose } e^{c} \\
\left(\text { No Pose } e^{c}\right)\end{array}$ & $\begin{array}{l}\text { No Pose } \\
\left(\text { No Pose }^{c}\right)\end{array}$ \\
\hline 12 & -2.294 & -28.001 & $\begin{array}{l}-4.520 \\
(-4.985)\end{array}$ & $\begin{array}{l}-24.374 \\
(-24.643)\end{array}$ & 27 & -2.075 & -26.515 & $\begin{array}{l}\text { No Pose } \\
(-4.124)\end{array}$ & $\begin{array}{l}\text { No Pose } \\
(-23.229)\end{array}$ \\
\hline 13 & -0.620 & -21.651 & $\begin{array}{l}-4.494 \\
(-4.492)\end{array}$ & $\begin{array}{l}-16.771 \\
(-21.190)\end{array}$ & 28 & -2.585 & -18.917 & $\begin{array}{l}-4.089 \\
(-3.731)\end{array}$ & $\begin{array}{l}-19.015 \\
(-22.840)\end{array}$ \\
\hline 14 & -2.121 & -29.366 & $\begin{array}{l}-4.559 \\
\left(\text { No Pose }^{\mathrm{c}}\right)\end{array}$ & $\begin{array}{l}-25.777 \\
(\text { No Pose })\end{array}$ & 29 & -0.386 & -20.876 & $\begin{array}{l}-4.089 \\
(-3.514)\end{array}$ & $\begin{array}{l}-24.208 \\
(-22.723)\end{array}$ \\
\hline 15 & -2.075 & -26.515 & $\begin{array}{l}-3.880 \\
(-4.124) \\
\end{array}$ & $\begin{array}{l}-24.932 \\
(-23.229)\end{array}$ & - & - & - & - & - \\
\hline
\end{tabular}

${ }^{\mathrm{a}}$ The results of B chain are given in parenthesis for $5 \mathrm{JZN}$.

$\mathrm{b}$ in $\mathrm{kcal} / \mathrm{mol}$

${ }^{\mathrm{c}}$ No interaction is calculated between compound and target protein

According to Table 1, related compounds are interacted with mentioned heat schock protein which PDB ID is 4PO2. The whole compounds appear to interact with almost good. However, the finding the better compounds is the aim of this study. Therefore, two parameters which are docking score and interaction energies are examined in detail. The docking score is an empirical scoring function designed to maximize separation of compounds with strong binding 
affinity from those with little to no binding ability. Interaction energy shows the relationship between compounds and proteins. The compounds (1) and (2) have been usually used nowadays. The main focus is the searching the better compounds than these two compounds. When these two parameters are examined in detail, three compounds are stand
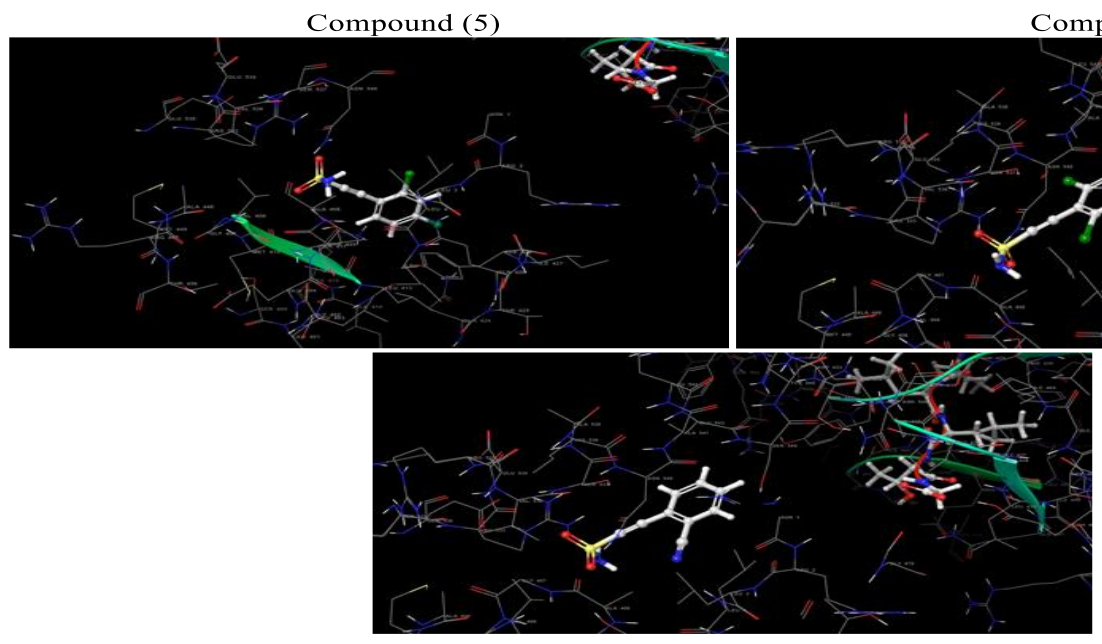

out which are compound (5), (12) and (20). Docking scores and interaction energies of the related three compounds are better than those of compound (1) and (2). The compound - protein complex structures belong to mentioned compounds are represented in Figure 6.

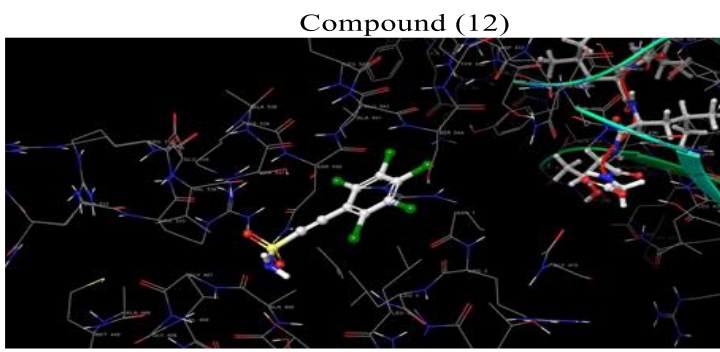

Compound (20)

Figure 6. The compound - protein complex structure.

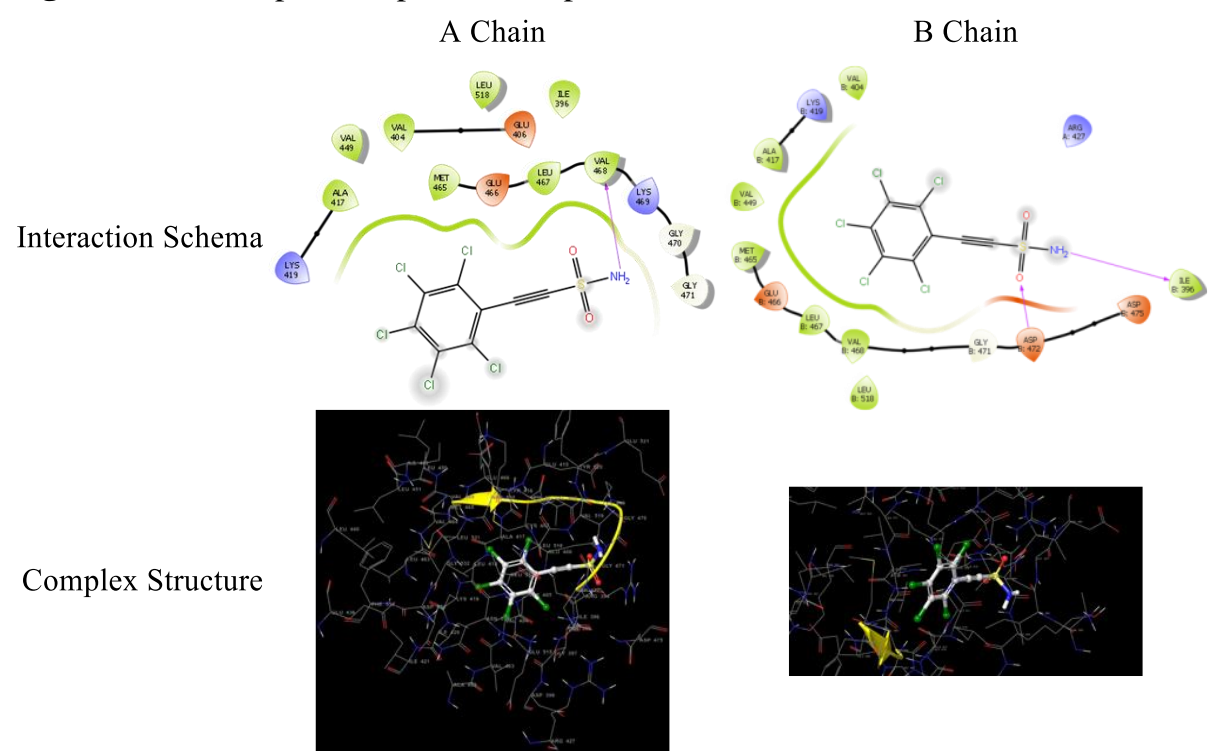

Figure 7. The interaction schema and compound-protein complex structure.

According to Figure 6 and docking results compounds with chlorine atom seem as popular in these interaction. The amino acids which are arginine, leucine, alanine, valine and serine play the significant role in the interaction between compound and target protein. Additionally, the interactions between studied compounds and 5JZN are examined in detail. There are two chains in this proteins which are called as A and B Chain. The docking results are given in Table 1. According to this table, the best compound is searched respect to compound (1) and (2). In A Chain, compound (12), (14) and (20) has been found as the better compounds than compound (1) and (2). However, there is no interaction between the last two compounds and $\mathrm{B}$ chain of $5 \mathrm{JZN}$ protein. According to the obtained results, compound (12) is found as the best compound in the protection and 
prevention from gastric cancer. The docking score and interaction energies are calculated as -4.520 , 24.374 for A Chain; -4.985 and -24.643 for B Chain, respectively. The interaction schema and complex structure of compound (12) is represented in Figure 7.

According to Figure 7, the main interaction types are hydrogen bond, $\pi-\pi$ interaction, dipole dipole interaction and solvent exposure in the both interaction. There is a hydrogen bond between amine site and valine in A chain while there are two hydrogen bonds in B Chain. These bonds strength the interaction between compound and protein.

\subsection{Assessment of Absorption, Distribution, Metabolism and Excretion (ADME)}

To estimate solubility and permeability of the designed PES-derives the computational study was performed. SwissADME online property calculation tool (http://www.swissadme.ch/index.php) was utilized for the prediction of drug-likeness properties.

Table 2. The ADME prediction for the PES, PES-Cl and newly designed inhibitors.

\begin{tabular}{|c|c|c|c|c|c|c|c|c|}
\hline \multirow[t]{2}{*}{ Compound } & \multirow[t]{2}{*}{$\% \mathbf{A B S}$} & \multirow[t]{2}{*}{ TPSA } & \multirow[t]{2}{*}{ Log S at pH 7.4} & \multicolumn{5}{|l|}{ Parameter } \\
\hline & & & & MW & cLog P & nHBA & nHBD & $\mathbf{R B}$ \\
\hline (1) & 85.35 & 68.54 & -2.01 & 181.21 & 0.71 & 3 & 1 & 0 \\
\hline (2) & 85.35 & 68.54 & -2.60 & 215.66 & 1.57 & 3 & 1 & 0 \\
\hline (3) & 85.35 & 68.54 & -2.60 & 215.66 & 1.31 & 3 & 1 & 0 \\
\hline (4) & 85.35 & 68.54 & -3.18 & 250.10 & 1.82 & 3 & 1 & 0 \\
\hline (5) & 85.35 & 68.54 & -3.76 & 284.55 & 2.63 & 3 & 1 & $\mathbf{0}$ \\
\hline (6) & 85.35 & 68.54 & -2.16 & 199.20 & 1.04 & 4 & 1 & 0 \\
\hline (7) & 85.35 & 68.54 & -2.31 & 217.19 & 1.40 & 5 & 1 & 0 \\
\hline (8) & 85.35 & 68.54 & -2.46 & 235.18 & 1.96 & 6 & 1 & 0 \\
\hline (9) & 85.35 & 68.54 & -2.91 & 260.11 & 1.67 & 3 & 1 & 0 \\
\hline (10) & 85.35 & 68.54 & -3.81 & 339.00 & 2.29 & 3 & 1 & 0 \\
\hline (11) & 85.35 & 68.54 & -4.71 & 417.90 & 2.54 & 3 & 1 & 0 \\
\hline (12) & 85.35 & 68.54 & -4.95 & 353.44 & 3.32 & 3 & 1 & $\mathbf{0}$ \\
\hline (13) & 85.35 & 68.54 & -2.78 & 271.16 & 2.22 & 8 & 1 & 0 \\
\hline (14) & 85.35 & 68.54 & -6.53 & 575.69 & 4.12 & 3 & 1 & 0 \\
\hline (15) & 75.20 & 97.97 & -1.68 & 210.21 & 0.62 & 5 & 1 & 1 \\
\hline (16) & 75.20 & 97.97 & -1.68 & 210.21 & 0.58 & 5 & 1 & 1 \\
\hline$(17)$ & 75.20 & 97.97 & -1.68 & 210.21 & 0.58 & 5 & 1 & 1 \\
\hline (18) & 77.14 & 92.33 & -1.94 & 206.22 & 0.50 & 4 & 1 & 0 \\
\hline (19) & 77.14 & 92.33 & -1.94 & 206.22 & 0.44 & 4 & 1 & 0 \\
\hline$(20)$ & 77.14 & 92.33 & -1.94 & 206.22 & 0.46 & 4 & 1 & $\mathbf{0}$ \\
\hline (21) & 78.37 & 88.77 & -1.86 & 197.21 & 0.60 & 4 & 2 & 0 \\
\hline$(22)$ & 78.37 & 88.77 & -1.86 & 197.21 & 0.31 & 4 & 2 & 0 \\
\hline$(23)$ & 78.37 & 88.77 & -1.86 & 197.21 & 0.59 & 4 & 2 & 0 \\
\hline (24) & 85.35 & 68.54 & -2.34 & 208.21 & 0.38 & 4 & 1 & 0 \\
\hline$(25)$ & 85.35 & 68.54 & -2.34 & 208.21 & 0.38 & 4 & 1 & 0 \\
\hline (26) & 85.35 & 68.54 & -2.34 & 208.21 & 0.38 & 4 & 1 & 0 \\
\hline (27) & 75.20 & 97.97 & -1.68 & 210.21 & 0.62 & 5 & 1 & 1 \\
\hline$(28)$ & 75.20 & 97.97 & -1.68 & 210.21 & 0.58 & 5 & 1 & 1 \\
\hline (29) & 75.20 & 97.97 & -1.68 & 210.21 & 0.58 & 5 & 1 & 1 \\
\hline
\end{tabular}

TPSA: Topological Polar Surface Area; \%ABS = 109-(0.345 X TPSA); Log S: Solubility; MW: Molecular Weight; Log P: Octanol-water partition coefficient; nHBA: Number hydrogen bond acceptor; nHBD: Number hydrogen bond donors; RB: Number Rotatable Bonds.

Lipinski's "rule of five" parameters indicating molecular weight $(\mathrm{MW})$, lipophilicity $(\log \mathrm{P})$, number of rotatable bonds, number of hydrogen bond donors and acceptor were calculated in silico using the SwissADME tool kit. According to Lipinski's rules a compound should present a molecular weight $<500 \mathrm{~g} / \mathrm{mol}$, a calculated $\log \mathrm{P}<$ 5 , a number of hydrogen bond acceptors $\leq 10$ and a 
number of hydrogen bond donors $\leq 5$. Furthermore, when the compounds that violate more than one of these rules bioavailability issues may occur. According to these criteria, compound 5, 12 and 20 obeyed Lipinski's rule of five and do not show any violation. Hence, these newly designed three compounds were predicted to have good bioavailability. Compounds (5) and (12) showed same absorption (\%ABS) and cell membrane permeation characteristics with (1) and (2). Meanwhile, they showed different polar-nonpolar partition coefficient characteristics from (1) and (2). Our findings also displayed that compounds 5 and 12 exhibited better solubility characteristics when compared to compound (1) and (2). However, compound 20 showed lower solubility and absorption characteristics compared to compounds (1), (2), (5) and (12).

\section{Conclusion}

Newly designed 30 different 2-Phenylethyne-1Sulfonamide derivatives which are potential heat shock protein 70 inhibitors are investigated by computational chemistry methods. Initially, related compounds are optimized B3LYP/6-31+G(d,p) level in water. C-PCM method is taken into consideration in solvent phase calculations. The chemical reactive regions are determined by using molecular orbital energy diagram, contour plots of molecular orbital and molecular electrostatic potential map. The optimized structures of studied compounds are accepted as orginal structure for docking calculations. The orginal structures and possible ones at $\mathrm{pH}=7 \pm 2$ are calculated by using LigPrep module. All structures are taken into account for docking calculations. Then, molecular docking calculations are done between the related structures and 4PO2. It is found that compound (5), (12) and (20) are found as the better ones than those of compound (1) and (2). Also, compound (5), (12) and (20) are found as the better ones for 5JZN like as in 4PO2. Drug likeness studies are performed via pharmacological absorption, distribution, metabolism, and excretion (ADME) properties estimation. According to ADME analyses, the drug properties of (5) and (12) were found as the better than those of compound (1), (2) and (20). Finally, it is pointed out that compounds (5) and (12) could be potential candidates for heat shock protein 70 inhibition and anticancer agent.

\section{Acknowledgements}

This work is supported by the Scientific Research Project Fund of Sivas Cumhuriyet University (CUBAP) under the project number RGD-020. This research was made possible by TUBITAK ULAKBIM, High Performance and Grid Computing Center (TR-Grid e-Infrastructure).

\section{References}

[1] S. Chatterjee, T. F. Burns, Targeting Heat Shock Proteins in Cancer: A Promising Therapeutic Approach, Int J Mol Sci. 18 (2017) E1978.

[2] P. C. Ikwegbue, P. Masamba, B. E. Oyinloye, A. P. Kappo, Roles of Heat Shock Proteins in Apoptosis, Oxidative Stress, Human Inflammatory Diseases, and Cancer, Pharmaceuticals (Basel) 11 (2018) E2.

[3] M. V. Powers, P. A. Clarke, P. Workman, Death by chaperone: HSP90, HSP70 or both?, Cell Cycle. 8 (2009) 518-526.

[4] M. Y. Sherman, V. L. Gabai, Hsp70 in cancer: back to the future, Oncogene. 34 (2015) 41534161.

[5] R. Schlecht, S R. Scholz, H. Dahmen, A. Wegener, C. Sirrenberg, D. Musil, J. Bomke, H. M. Eggenweiler, M. P. Mayer, B. Bukau, Functional Analysis of Hsp70 Inhibitors, PLoS One 8 (2013) e78443.

[6] J. Radons, The human HSP70 family of chaperones: where do we stand?, Cell Stress Chaperones. 21 (2016) 379-404.

[7] A. Rodina, P. D. Patel, Y. Kang, Y. Patel, I. Baaklini, M. J. Wong, T. Taldone, P. Yan, C. Yang, R. Maharaj, A. Gozman, M. R. Patel, H. J. Patel, W. Chirico, H. ErdjumentBromage, T. T. Talele, J. C. Young, G. Chiosis, Identification of an Allosteric Pocket on Human Hsp70 Reveals a Mode of Inhibition of This Therapeutically Important Protein, Chem Biol. 20 (2013) 1469-1480.

[8] D. Lanneau, A. de Thonel, S, Maurel, C. Didelot, C. Garrido, Apoptosis Versus Cell Differentiation, Prion. 1 (2007) 53-60.

[9] M. E. Murphy, The HSP70 family and cancer, Carcinogenesis. 34 (2013) 1181-1188.

[10] A. R. Goloudina, O. N. Demidov, C. Garrido, Inhibition of HSP70: A challenging anticancer strategy, Cancer Lett. 325 (2012) 117124.

[11] G. D.Lianos, G. A. Alexiou, A. Mangano, A. Mangano, S. Rausei, L. Boni, G. Dionigi, D. 
H. Roukos, The role of heat shock proteins in cancer, Cancer Lett. 360 (2015) 114-118.

[12] S. Kumar, J. Stokes, U. P Singh, K. Scissum Gunn, A. Acharya, U. Manne, M. Mishra, Targeting Hsp70: A possible therapy for cancer, Cancer Lett. 374 (2016) 156-166.

[13] J. A.Yaglom, V. L. Gabai, M. Y. Sherman, High Levels of Heat Shock Protein Hsp72 in Cancer Cells Suppress Default Senescence Pathways, Cancer Res. 67 (2007) 2373-2381.

[14] E. Zorzi, P. Bonvini, Inducible Hsp70 in the Regulation of Cancer Cell Survival: Analysis of Chaperone Induction, Expression and Activity, Cancers (Basel) 3 (2011) 3921-3956.

[15] G. Jego, A. Hazoumé, R. Seigneuric, C. Garrido, Targeting heat shock proteins in cancer, Cancer Lett. 332 (2013) 275-285.

[16] M. V. Powers, K. Jones, C. Barillari, I. Westwood, R. L. van Montfort, P. Workman, Targeting HSP70: The second potentially druggable heat shock protein and molecular chaperone?, Cell Cycle. 9 (2010) 1542-1550.

[17] H. Wang, L. Bu, C. Wang, Y. Zhang, H. Zhou, X. Zhang, W. Guo, C. Long, D. Guo, X. Sun, The Hsp70 inhibitor 2phenylethynesulfonamide inhibits replication and carcinogenicity of Epstein-Barr virus by inhibiting the molecular chaperone function of Hsp70, Cell Death Dis. 9 (2018) 734.

[18] G. M. Balaburski, J. I. Leu, N. Beeharry, S. Hayik, M. D. Andrake, G. Zhang, M. Herlyn, J. Villanueva, R. L. Jr. Dunbrack, T. Yen, D. L. George, M. E. Murphy, A modified HSP70 inhibitor shows broad activity as an anticancer agent, Mol Cancer Res. 11 (2013) 219-229.

[19] R. D. Dennington II, T. A. Keith and J. M. Millam, GaussView 5.0, Wallingford, CT, 2009.

[20] Perkin Elmer, ChemBioDraw Ultra Version (15.1.0.144), CambridgeSoft Waltham, MA, USA, 2016.

[21] Gaussian 09, Gaussian AS64L-G09RevD.01, M. J. Frisch, G. W. Trucks, H. B. Schlegel, G. E. Scuseria, M. A. Robb, J. R. Cheeseman, G. Scalmani, V. Barone, G. A. Petersson, H. Nakatsuji, X. Li, M. Caricato, A. V. Marenich, J. Bloino, B. G. Janesko, R. Gomperts, B. Mennucci, H. P. Hratchian, J. V. Ortiz, A. F. Izmaylov, J. L. Sonnenberg, D. WilliamsYoung, F. Ding, F. Lipparini, F. Egidi, J. Goings, B. Peng, A. Petrone, T. Henderson, D. Ranasinghe, V. G. Zakrzewski, J. Gao, N. Rega, G. Zheng, W. Liang, M. Hada, M.
Ehara, K. Toyota, R. Fukuda, J. Hasegawa, M. Ishida, T. Nakajima, Y. Honda, O. Kitao, H. Nakai, T. Vreven, K. Throssell, J. A. Montgomery, Jr., J. E. Peralta, F. Ogliaro, M. J. Bearpark, J. J. Heyd, E. N. Brothers, K. N. Kudin, V. N. Staroverov, T. A. Keith, R. Kobayashi, J. Normand, K. Raghavachari, A. P. Rendell, J. C. Burant, S. S. Iyengar, J. Tomasi, M. Cossi, J. M. Millam, M. Klene, C. Adamo, R. Cammi, J. W. Ochterski, R. L. Martin, K. Morokuma, O. Farkas, J. B. Foresman, and D. J. Fox, Gaussian, Inc., Wallingford CT, 2009.

[22] A. D. Becke, Density-functional thermochemistry. III. The role of exact exchange, J. Chem. Phys. 98 (1993) 56485652.

[23] R. Ditchfield, W. J. Hehre, J. A. Pople, SelfConsistent Molecular-Orbital Methods. IX. An Extended Gaussian-Type Basis for Molecular-Orbital Studies of Organic Molecules, J. Chem. Phys. 54 (1971) 724-728.

[24] W. J. Hehre, R. Ditchfield, J. A. Pople, SelfConsistent Molecular Orbital Methods. XII. Further Extensions of Gaussian-Type Basis Sets for Use in Molecular Orbital Studies of Organic Molecules, J. Chem. Phys. 56 (1972) 2257-2261.

[25] P. C. Hariharan, J. A. Pople, The influence of polarization functions on molecular orbital hydrogenation energies, Theor. Chem. Acc. 28 (1973) 213-222.

[26] P. C. Hariharan, J. A. Pople, Accuracy of AH $\mathrm{n}$ equilibrium geometries by single determinant molecular orbital theory, Mol. Phys. 27 (1974) 209-214.

[27] M. S. Gordon, The isomers of silacyclopropane, Chem. Phys. Lett. 76 (1980) 163-168.

[28] M. M. Francl, W. J. Pietro, W. J. Hehre, J. S. Binkley, D. J. DeFrees, J. A. Pople, M. S. Gordon, Self-consistent molecular orbital methods. XXIII. A polarization-type basis set for second-row elements, J. Chem. Phys. 77 (1982) 3654-3665.

[29] R. C. Binning Jr., L. A. Curtiss, Compact contracted basis sets for third-row atoms: $\mathrm{Ga}-$ Kr, J. Comp. Chem. 11 (1990) 1206-1216.

[30] J. -P. Blaudeau, M. P. McGrath, L. A. Curtiss, L. Radom, Extension of Gaussian-2 (G2) 
theory to molecules containing third-row atoms K and Ca, J. Chem. Phys. 107 (1997) 5016-5021.

[31] V. A. Rassolov, J. A. Pople, M. A. Ratner, T. L. Windus, 6-31G* basis set for atoms $\mathrm{K}$ through Zn, J. Chem. Phys. 109 (1998) 12231229.

[32] V. A. Rassolov, M. A. Ratner, J. A. Pople, P. C. Redfern, L. A. Curtiss, 6-31G* basis set for third-row atoms, J. Comp. Chem. 22 (2001) 976-984.

[33] Gaussian 09, Gaussian Gaussian IA32WG09RevA.02, M. J. Frisch, G. W. Trucks, H. B. Schlegel, G. E. Scuseria, M. A. Robb, J. R. Cheeseman, G. Scalmani, V. Barone, G. A. Petersson, H. Nakatsuji, X. Li, M. Caricato, A. V. Marenich, J. Bloino, B. G. Janesko, R. Gomperts, B. Mennucci, H. P. Hratchian, J. V. Ortiz, A. F. Izmaylov, J. L. Sonnenberg, D. Williams-Young, F. Ding, F. Lipparini, F. Egidi, J. Goings, B. Peng, A. Petrone, T. Henderson, D. Ranasinghe, V. G. Zakrzewski, J. Gao, N. Rega, G. Zheng, W. Liang, M. Hada, M. Ehara, K. Toyota, R. Fukuda, J. Hasegawa, M. Ishida, T. Nakajima, Y. Honda, O. Kitao, H. Nakai, T. Vreven, K. Throssell, J. A. Montgomery, Jr., J. E. Peralta, F. Ogliaro, M. J. Bearpark, J. J. Heyd, E. N. Brothers, K. N. Kudin, V. N. Staroverov, T. A. Keith, R. Kobayashi, J. Normand, K. Raghavachari, A. P. Rendell, J. C. Burant, S. S. Iyengar, J. Tomasi, M. Cossi, J. M. Millam, M. Klene, C. Adamo, R. Cammi, J. W. Ochterski, R. L. Martin, K. Morokuma, O. Farkas, J. B. Foresman, and D. J. Fox, Gaussian, Inc., Wallingford CT, 2009.

[34] N. M. O'Boyle, A. L. Tenderhold, K. M. Langner, A library for package-independent computational chemistry algorithms, J. Comp. Chem. 29 (2008) 839-845.

[35] E. Harder, W. Damm, J. Maple, C. Wu, M. Reboul, J. Y. Xiang, L. Wang, D. Lupyan, M. K. Dahlgren, J. L. Knight, J. W. Kaus, D. Cerutti, G. Krilov, W. L. Jorgensen, R. Abel, R. A. Friesner, OPLS3: A Force Field Providing Broad Coverage of Drug-like Small
Molecules and Proteins, J. Chem. Theory Comput. 12 (2016) 281-296.

[36] R. A. Friesner, R. B. Murphy, M. P. Repasky, L. L. Frye, J. R. Greenwood, T. A. Halgren, P. C. Sanschagrin, D. T. Mainz, Extra precision glide: docking and scoring incorporating a model of hydrophobic enclosure for protein-ligand complexes, J. Med. Chem. 49 (2006) 6177-6196.

[37] T. A. Halgren, R. B. Murphy, R. A. Friesner, H. S. Beard, L. L. Frye, W. T. Pollard, J. L. Banks, Glide: a new approach for rapid, accurate docking and scoring. 2. Enrichment factors in database screening, J. Med. Chem. 47 (2004) 1750-1759.

[38] R. A. Friesner, J. L. Banks, R. B. Murphy, T. A. Halgren, J. J. Klicic, D. T. Mainz, M. P. Repasky, E. H. Knoll, D. E. Shaw, M. Shelley, J. K. Perry, P. Francis, P. S. Shenkin, Glide: A New Approach for Rapid, Accurate Docking and Scoring. 1. Method and Assessment of Docking Accuracy, J. Med. Chem. 47 (2004) 17391749.

[39] A. Daina, O. Michielin, V. Zoete, iLOGP: A Simple, Robust, and Efficient Description of n-Octanol/Water Partition Coefficient for Drug Design Using the GB/SA Approach, J. Chem. Inf. Model. 54(12) (2014) 3284-3301.

[40] P. Zhang, J. I. -Ju Leu, M. E. Murphy, D. L. George, R. Marmorstein, Crystal structure of the stress-inducible human heat shock protein 70 substrate-binding domain in complex with Peptide substrate, PLOS One 9(7) (2014) e103518.

[41] O. Patel, W. Dai, M. Mentzel, M. D. W. Griffin, J. Serinoux, Y. Gay, S. Fischer, S. Sterle, A. Kropp, C. J. Burns, M. Ernst, M. Buchert, I. S. Lucet, Biochemical and Structural Insights into Doublecortin-like Kinase Domain 1, Structure 24 (2016) 1550-1561. 